\title{
Human Chorionic Gonadotropin Mediated Generation of Reactive Oxygen Species Is Sufficient to Induce Meiotic Exit but Not Apoptosis in Rat Oocytes
}

\author{
Meenakshi Tiwari and Shail K. Chaube*
}

\begin{abstract}
Generation of reactive oxygen species (ROS) is associated with final stages of follicular development and ovulation in mammals. The human chorionic gonadotropin ( $\mathrm{hCG}$ ) mimics the action of luteinizing hormone and triggers follicular development and ovulation. However, it remains unclear whether hCG induces generation of ROS, if yes, whether hCG-mediated increased level of ROS could induce meiotic exit and/or apoptosis in rat oocytes. For this purpose, cumulus-oocyte complexes (COCs) were collected from ovary of experimental rats injected with $20 \mathrm{IU}$ pregnant mare's serum gonadotropin for $48 \mathrm{~h}$ followed by $20 \mathrm{IU} \mathrm{hCG}$ for $0,7,14$, and $21 \mathrm{~h}$. The morphological changes in COCs, meiotic status of oocyte, total ROS, hydrogen peroxide $\left(\mathrm{H}_{2} \mathrm{O}_{2}\right)$, inducible nitric oxide synthase (iNOS), nitric oxide (NO), Bax, Bcl-2, cytochrome c, telomerase reverse transcriptase (TERT) expression levels, and DNA fragmentation were analyzed in COCs. Our data suggest that hCG surge increased total ROS as well as $\mathrm{H}_{2} \mathrm{O}_{2}$ levels but decreased iNOS expression and total NO level in oocytes. The hCG-mediated increased level of ROS was sufficient to induce meiotic cell cycle resumption in majority of oocytes as evidenced by meiotic exit from diplotene as well as metaphase-II (M-II) arrest and their meiotic status. However, increase of ROS level due to hCG surge was not sufficient to trigger Bax and cytochrome c expression levels and DNA fragmentation in COCs. In addition, increased TERT activity was observed in oocytes collected $21 \mathrm{~h}$ post-hCG surge showing onset of oocyte aging. Taken together, these results suggest that hCG induces generation of ROS sufficient to trigger meiotic exit from diplotene, as well as M-II arrest, but not good enough to induce apoptosis in rat oocytes.
\end{abstract}

Keywords: rat cumulus-oocyte complexes; ROS; meiotic exit; TERT; DNA fragmentation

\section{Introduction}

Ovary is a metabolically active organ that generates excess amount of reactive oxygen species (ROS) during final stages of follicular development, maturation, and ovulation. ${ }^{1-4}$ During this period, oocyte achieves meiotic competency within the antral follicle just before ovulation in mammals. ${ }^{5-8}$ The meiotic competency starts when oocyte resumes meiosis from diplotene stage. ${ }^{1,9}$ The diplotene stage is morphologically identified by the presence of germinal vesicle (GV) and nucleolus in the oocyte cytoplasm..$^{5-10}$ The diplotene stage may last for several months to several years in various mammals. ${ }^{1,2,11-13}$ The cell cycle arrest for such a long period could be due to several factors either released from encircling granulosa cells or by oocyte itself. ${ }^{5,10}$ Granulosa cells play important role in the synthesis and secretion of various signal molecules required for the maintenance of meiotic arrest at diplotene stage. ${ }^{2,6,11-15}$

Acquisition of meiotic competency in oocytes starts with resumption from diplotene arrest, $, 5,13,16-18$ progress through metaphase-I (M-I), and ends with the achievement of metaphase-II (M-II) stage by extruding first polar body (PBI) in most of the mammalian 
species. ${ }^{6,11,12,19-25}$ Pituitary gonadotropin(s) surge induces follicular development, maturation, and ovulation. $^{26,27}$ The increased metabolic activity during follicular development or increased inflammation during follicular rupture at the time of ovulation may cause the generation of ROS., ${ }^{3,4}$ The increased level of ROS has been observed during luteinizing hormone (LH)induced ovarian stimulation protocol. ${ }^{4,28}$ The increase in level of ROS associates with meiotic resumption, fertilization, and improved reproductive outcome in human. ${ }^{29,30}$ In contrast, excess amount of ROS could induce susceptibility towards oocyte apoptosis. ${ }^{31-38}$

Human chorionic gonadotropin (hCG) has commonly been used in ovarian stimulation protocol to induce final maturation and ovulation in several mammalian species during assisted reproduction. ${ }^{28,39}$ Due to structural and biological similarities with LH, hCG binds to LH receptors. ${ }^{39}$ It is proposed that hCG surge generates ROS due to increased cell proliferation during final stages of folliculogenesis and mediate meiotic resumption. ${ }^{2,4}$ Another source of ROS could be the inflammation generated due to follicular rupture during ovarian stimulation protocol. This notion is supported by the observations that the depletion of ROS impairs ovulation.,

Pituitary gonadotropins modulate expressions of various nitric oxide synthase (NOS) isoforms. ${ }^{40}$ Both pregnant mare's serum gonadotropin (PMSG) and hCG have been shown to influence inducible nitric oxide synthase (iNOS) expressions in rat ovary. ${ }^{41}$ Recent studies from our laboratory suggest that decreased level of nitric oxide (NO) is associated with meiotic exit from diplotene, as well as M-II arrest, ${ }^{12,17,22}$ while high level of NO induces cell cycle arrest and apoptosis. ${ }^{31,33}$

After ovulation, oocyte experiences aging process, ${ }^{42-44}$ which can be determined by telomerase reverse transcriptase (TERT) activity. ${ }^{45}$ The increased TERT activity has recently been reported during postovulatory egg aging in rat. ${ }^{25}$ Oxidative stress may result in shortening of telomere length. ${ }^{45}$ Recent studies from our laboratory suggest that increased oxidative stress reduces Bcl-2 expression and increased TERT activity. ${ }^{25,36-38}$ However, it remains unclear whether hCG-mediated generation of ROS triggers meiotic resumption. If yes, whether, its amount is sufficient to induce apoptosis. Therefore, present study was aimed to find out the impact of hCG surge on ROS, hydrogen peroxide $\left(\mathrm{H}_{2} \mathrm{O}_{2}\right)$, iNOS, NO, Bax, Bcl-2, cytochrome c, TERT expression, and DNA fragmentation in rat cumulus-oocyte complexes (COCs).

\section{Materials and Methods}

Chemicals and preparation of culture medium

Chemicals used in present study were purchased from Sigma Chemical Co., St. Louis, MO, and culture media from HiMedia Laboratories, Mumbai, India unless otherwise specified. Culture medium (AL094A, M-199) was prepared as per the company manual protocol. The sodium bicarbonate $(0.035 \% \mathrm{w} / \mathrm{v})$ was added, and the $\mathrm{pH}$ was adjusted to $7.2 \pm 0.05$. The osmolarity was checked ( $290 \pm 5 \mathrm{~m}$ Osmol) and then medium was supplemented with antibiotics, that is, L-glutamine, penicillin, and streptomycin (GPS; $1 \mu \mathrm{L} / \mathrm{mL}$; Cat. No. A007). The culture medium was stored at $4^{\circ} \mathrm{C}$ and discarded if not used within 15 days.

\section{Collection of COCs}

Experimental immature female rats (Rattus norvegicus) of Charles-Foster strain (22-24 days old; $45 \pm 5 \mathrm{~g}$ body weight) were housed in light-controlled room with food and water in ad libitum. For the first series of experiments, rats were subjected to a single subcutaneous injection of 20 IU PMSG for $48 \mathrm{~h}$ and 20 IU hCG for $0,7,14$, and $21 \mathrm{~h}$. Thereafter, rats were euthanized, and ovary along with fallopian tube was collected in $35-\mathrm{mm}$ Petri dish containing $2 \mathrm{~mL}$ of prewarmed culture medium-199 (M-199). The ovary was punctured using a 26-gauge needle attached to $1 \mathrm{~mL}$ of tuberculin syringe under a stereomicroscope (Nikon type 104, Japan) for the collection of diplotene, as well as exit from diplotene arrest (EDA) COCs, while M-II and exit from metaphase-II (EM-II) stages of COCs were collected from the ampulla of fallopian tube. A group of 12-14 COCs were collected using microtubing attached with disposable glass micropipette (Clay Adams, NJ) and few of them were partially denuded by manual pipetting using hyaluronidase $(0.01 \%)$. COCs and denuded oocytes were transferred on slide and fixed with $4 \%$ buffered formaldehyde. In the second series of experiment, COCs were collected from ovary, as well as ampulla of fallopian tube, as described for first series of experiments. The COCs were denuded and immediately used for the quantitative analysis of $\mathrm{H}_{2} \mathrm{O}_{2}$ and total NO levels. In the present study, three independent experiments were conducted using total 60 experimental animals to collect COCs and denuded oocytes sufficient for morphological, biochemical, and immunofluorescence studies. All procedures conformed to the provisions of institutional animal ethics committee of the university (Wide Letter No. F.Sc./IAEC/2014-15/0248) and in accordance with the 
institutional practice and within the framework of experimentation of Animals (Scientific Procedure) Act of 2007, of committee for the purpose of supervision and control on experiments on animals (CPSCEA), Government of India.

\section{Determination of meiotic status of oocytes}

The COCs were partially denuded by repeated manual pipetting several times and after washing with M-199; meiotic status of oocytes was confirmed by Hoechst33342 using fluorescence microscope (Model, Ni-U; Nikon Eclipse Tokyo, Japan). For this purpose, 1214 denuded oocytes collected from each group of animals were washed twice with phosphate-buffered saline (PBS) and then incubated $(10 \mathrm{~min})$ with $10 \mu \mathrm{g} / \mathrm{mL}$ of Hoechst33342 in PBS. Thereafter, denuded oocytes were washed 10 times with PBS and then checked for their meiotic status under fluorescence microscope at $350 \mathrm{~nm}$ (400x magnification). Three independent experiments were conducted to confirm the meiotic stage, and representative photographs are shown in the Results section.

\section{Analysis of total ROS level}

The total ROS level was analyzed using $2^{\prime}, 7^{\prime}$ dichlorodihydrofluorescein diacetate $\left(\mathrm{H}_{2} \mathrm{DCFDA}\right)$ following previous published protocol. ${ }^{18}$ Briefly, 12-14 COCs from each group were exposed to $\mathrm{H}_{2}$ DCFDA $(10 \mu \mathrm{M})$ for $15 \mathrm{~min}$ at $37^{\circ} \mathrm{C}$ in $\mathrm{CO}_{2}$ incubator (Galaxy 170 R; New Brunswick, Eppendorf AG, Hamburg, Germany, United Kingdom). Thereafter, COCs were washed five times with prewarmed PBS and then DCF fluorescence was measured at $485 \mathrm{~nm}$ excitation/ $520 \mathrm{~nm}$ emissions using fluorescence microscope (400× magnification). The denuded oocytes of corresponding COCs from three independent experiments were used for corrected total cell fluorescence (CTCF) analysis. All parameters were kept constant for each oocyte, and fluorescence intensity was analyzed using ImageJ software (version 1.44; National Institute of Health, Bethesda).

\section{Quantitative estimation of $\mathrm{H}_{2} \mathrm{O}_{2}$ concentration}

The $\mathrm{H}_{2} \mathrm{O}_{2}$ concentration was analyzed using Hydrogen Peroxide Assay Kit (Cat. No. K265-200) purchased from BioVision, CA. In brief, 36-42 COCs collected from each group were denuded by manual pipetting and lysed in hypotonic lysis buffer $(5 \mathrm{mM}$ Tris, $20 \mathrm{mM}$ ethyl diamine tetraacetic acid [EDTA], 0.5\% Triton X$100, \mathrm{pH} 8)$. Lysates were centrifuged at $10,000 \mathrm{~g}$ at $4^{\circ} \mathrm{C}$ for $30 \mathrm{~min}$, and supernatant was immediately used for quantitative estimation of $\mathrm{H}_{2} \mathrm{O}_{2}$ following previous published protocol. ${ }^{22}$ The optical density (OD) was determined using a microplate reader (Model: Micro Scan MS5608A; Electronics Corporation of India Limited, Hyderabad, India) set to $550 \mathrm{~nm}$. Samples from three independent experiments were used for each group, and all samples were run in one assay to avoid interassay variation, and intraassay variation was $2.3 \%$.

\section{Quantitative estimation of total NO concentration}

The total NO level was estimated using NO Assay Kit (Cat. No. KGE001) purchased from R\&D Systems (MN) following previous published protocol. ${ }^{17}$ Briefly, 36-42 COCs from each group were denuded by manual pipetting. The denuded oocytes were lysed in hypotonic lysis buffer ( $5 \mathrm{mM}$ Tris, $20 \mathrm{mM}$ EDTA, $0.5 \%$ Triton X-100, $\mathrm{pH} 8$ ) and centrifuged at $10,000 \mathrm{~g}$ at $4^{\circ} \mathrm{C}$ for $30 \mathrm{~min}$. The supernatant was stored at $-20^{\circ} \mathrm{C}$ until all samples were collected. All samples, working standards, and reagents were thawed, brought to room temperature, and prepared following company manual protocol. The reaction diluents $(50 \mu \mathrm{L})$ were added to the blank well and nitrate standards $(50 \mu \mathrm{L})$ or samples to remaining wells. The nicotinamide adenine dinucleotide (reduced form) $(25 \mu \mathrm{L})$ and then diluted nitrate reductase $(25 \mu \mathrm{L})$ were added to each and every well. The microplate was incubated at $37^{\circ} \mathrm{C}$ (30 min) and then Griess reagent I and II (50 $\mu \mathrm{L}$ each) were added. The plate was incubated $(10 \mathrm{~min})$ at room temperature and then OD was determined using a microplate reader set at $540 \mathrm{~nm}$ with wavelength correction at $690 \mathrm{~nm}$. Three independent samples were run in one assay to avoid interassay, and intra-assay variation was found to be $1.9 \%$.

Detection of iNOS, Bax, Bcl-2, cytochrome c, and TERT expressions

Immunofluorescence of iNOS, Bax, Bcl-2, and cytochrome $\mathrm{c}$ expressions were analyzed in COCs using their highly specific antibodies purchased from Santa Cruz Biotechnology (Dallas, TX), as per our published protocol with some modifications. ${ }^{36}$ In brief, $12-14$ COCs from each group were fixed with $4 \%$ buffered formaldehyde $(10 \mathrm{~min})$ at room temperature. Slides were washed thrice with prewarmed PBS and exposed to Triton X-100 $\left(0.01 \%\right.$ in PBS) for $10 \mathrm{~min}$ at $37^{\circ} \mathrm{C}$ for permeabilization. Slides were washed thrice with prewarmed PBS and then treated with sodium citrate solution $(0.01 \mathrm{M})$ at $37^{\circ} \mathrm{C}(10 \mathrm{~min})$ for better antigen retrieval. Slides were again washed thrice with 
prewarmed PBS and then incubated with blocking buffer $\left(2.5 \%\right.$ PBS-BSA solution) at $37^{\circ} \mathrm{C}(30 \mathrm{~min})$. Thereafter, slides were exposed to $100 \mu \mathrm{L}$ of their respective primary antibodies (NOS2 $(\mathrm{N}-20)$, rabbit polyclonal antibody (sc-651) raised against a peptide mapping near the N-terminus of NOS2; Bax (B-9), mouse monoclonal antibody (sc-7480) raised against amino acids 1-171 of Bax; Bcl-2 (C-9), mouse monoclonal antibody (sc-7382) raised against amino acids 1-205 of Bcl-2; cytochrome c (A-8), mouse monoclonal antibody (sc-13156) raised against amino acids 1-104 of cytochrome c; TERT (D-16), goat polyclonal antibody (sc-68720) raised against a peptide mapping within an internal region of TERT; and actin (C-2) mouse monoclonal antibody (sc-8432) specific for an epitope mapping between amino acids 350-375 at the c-terminus of actin, 1:500 dilutions in blocking buffer) at $37^{\circ} \mathrm{C}$ for $1 \mathrm{~h}$. After 6-8 washes with PBS, slides were exposed to $100 \mu \mathrm{L}$ of specific anti-rabbit fluorescein isothiocyanate (FITC)-labeled (sc-3839) secondary antibody for detection of iNOS, anti-mouse FITC-labeled (sc-2010) secondary antibody for detection of Bax, Bcl-2, cytochrome $\mathrm{c}$, and $\beta$-actin, and anti-goat FITC-labeled (sc-2024) secondary antibody for detection of TERT expression at $37^{\circ} \mathrm{C}$ in humidified chamber (1:1000 dilutions in blocking buffer). After $1 \mathrm{~h}$ of incubation, slides were washed five times with prewarmed PBS, mounted with fluorescence mounting medium by VECTASHIELD (Vector laboratories) and then observed under fluorescence microscope, $465 \mathrm{~nm}$ at $100 \times$ and $400 \times$ magnification. Fluorescence intensity of $\beta$-actin was analyzed in parallel as a control to assure that all parameters were kept constant during immunofluorescence analysis. The experiment was repeated thrice to confirm the results, and the representative photographs are shown in Results section.

\section{DNA fragmentation analysis}

The extent of DNA fragmentation was analyzed using acridine orange/ethidium bromide $(\mathrm{AO} / \mathrm{EtBr})$ staining as per our previous published protocol. ${ }^{38}$ In brief, the 12-14 COCs from each group were fixed in $4 \%$ buffered formaldehyde $(15 \mathrm{~min})$ and then air-dried. Slides were washed and then exposed to nucleic acid binding dye mix and $100 \mu \mathrm{L}$ of $1: 1$ mixture of $\mathrm{AO} / \mathrm{EtBr}$ solutions $(4 \mu \mathrm{g} / \mathrm{mL})$ for $1 \mathrm{~min}$ at room temperature. Slides were then washed with PBS and analyzed using fluorescence microscope. The viable cells and the extent of apoptosis were recognized depending on their color due to binding of EtBr to the fragmented DNA. Normal cells with intact DNA had green fluorescence of $\mathrm{AO}$, while $\mathrm{EtBr}$ binding to fragmented DNA changed the color from green to yellowish orange during initiation of apoptosis.

DNA fragmentation was further confirmed using terminal deoxynucleotidyl transferase dUTP nick end labeling (TUNEL) assay, that is, TACS 2TdT in situ Apoptosis Detection Kit purchased from Trevigen, Inc., MD (4812-30-K) following company manual protocol. The 12-14 COCs from each group were transferred and fixed in $4 \%$ buffered formaldehyde ( $15 \mathrm{~min})$. Slides were immersed in $1 \times$ PBS $(10 \mathrm{~min})$ and then treated with $50 \mu \mathrm{L}$ proteinase $\mathrm{K}$ solution ( $15 \mathrm{~min})$. The slides were washed with deionized water twice, $2 \mathrm{~min}$ each, and then immersed in $1 \times$ TdT labeling buffer ( $5 \mathrm{~min}$ ). The slides were then incubated with $50 \mu \mathrm{L}$ labeling reaction mix at $37^{\circ} \mathrm{C}$ in a humidity chamber for $1 \mathrm{~h}$. Thereafter, slides were immersed in $1 \times$ TdT stop buffer ( $5 \mathrm{~min}$ ) and then washed with $1 \times$ PBS for two times, 2 min each. Thereafter, slides were incubated with $50 \mu \mathrm{L}$ strep-fluor solution in dark $(20 \mathrm{~min})$ and then again washed with $1 \times$ PBS for two times, 2 min each. After that the slides were observed under fluorescence microscope at $495 \mathrm{~nm}$. The experiment was repeated thrice to confirm the results.

\section{Statistical analysis}

Data are expressed as mean \pm standard error of mean (SEM) of three independent experiments. All percentage data were subjected to arcsine square-root transformation before statistical analysis. Data were analyzed by one-way analysis of variance (ANOVA) using SPSS software, version 17.0 (SPSS, Inc., Chicago, IL) followed by Bonferroni post hoc analysis. A probability of $p<0.05$ was considered to be statistically significant.

\section{Results}

Changes in morphological and oocyte meiotic status during progression of meiotic cell cycle

As shown in Figure 1, COCs collected from PMSG (20 IU for $48 \mathrm{~h}$ )-treated animals show diplotene stage as evidenced by the presence of GV and nucleolus in the oocyte cytoplasm (blue arrow). These oocytes are encircled with several layers of granulosa cells (green arrow; Fig. 1A). The hCG (20 IU) surge for $7 \mathrm{~h}$ induced meiotic resumption from diplotene stage and progression to M-I stage as evidenced by disappearance of GV and nucleolus (yellow arrow; Fig. 1B). Majority of oocytes were arrested at M-II stage and posses PBI after $14 \mathrm{~h}$ of hCG surge (white arrow; Fig. 1C). These M-II arrested oocytes showed dispersed granulosa cell (green arrow). Ovulated COCs collected after $21 \mathrm{~h}$ post-hCG surge showed 

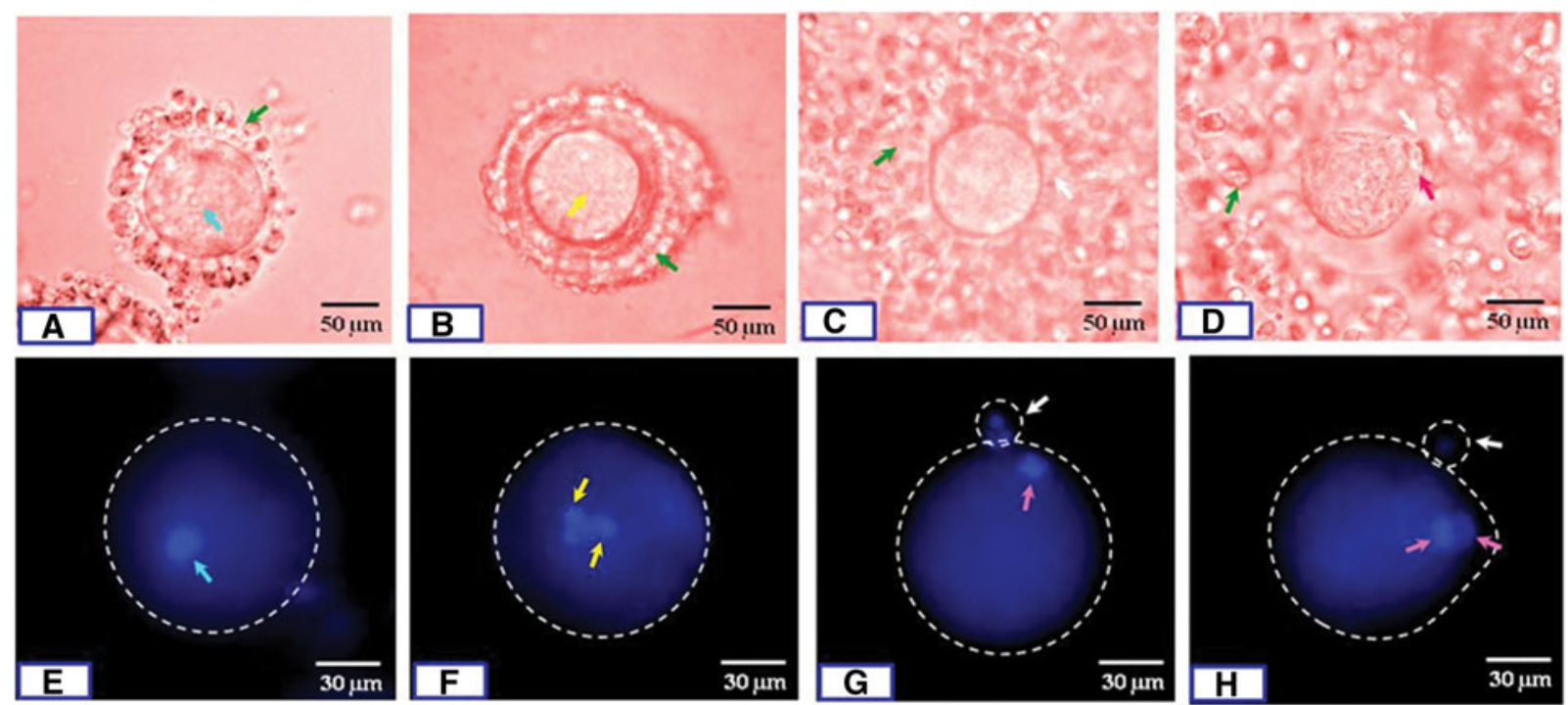

I

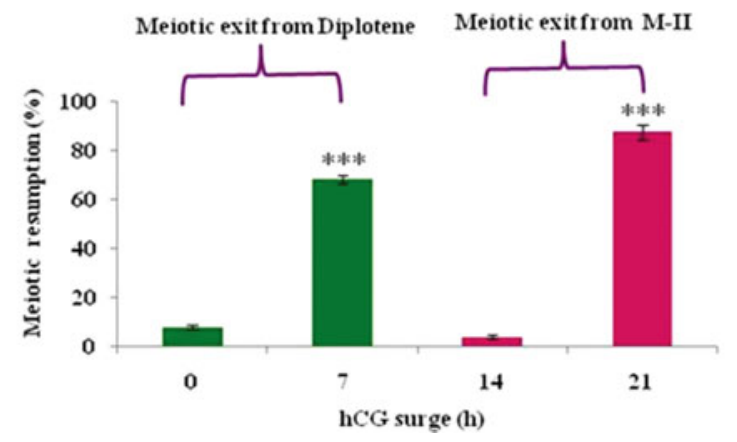

FIG. 1. Representative photograph showing morphological changes in COCs. Diplotene-arrested COCs collected from PMSG-treated animals showing GV, nucleolus (blue arrow), and tightly enclosed encircling granulosa cells (green arrow, A). hCG surge for $7 \mathrm{~h}$ induced meiotic resumption from diplotene arrest as evidenced by GVBD (yellow arrow) and dispersion of encircling granulosa cells (green arrow, B). The majority of oocytes were arrested at M-Il stage, possess PBI (white arrow) and granulosa cell dispersion (yellow arrow, C) after $14 \mathrm{~h}$ of hCG surge. The initiation of PBIl extrusion (pink arrow) was observed, if the COCs were collected from ampulla of fallopian tube after $21 \mathrm{~h}$ post-hCG surge (D). The diploid set of chromosomes confirms the diplotene stage (blue arrow, E), while formation of metaphase plate (yellow arrows, $\mathbf{F}$ ) indicates resumption of meiosis. M-II arrested oocyte is confirmed by haploid set of chromosome in oocyte (pink arrow, G) and another set in PBI (white arrow, G). The presence of haploid set of chromosome in PBI (white arrow, $\mathbf{H}$ ) and movement of another haploid set away from metaphase plate (pink arrows, $\mathbf{H}$ ) confirm meiotic exit from M-II arrest. hCG induced meiotic resumption from diplotene, as well as M-II arrest in majority of oocytes (I). Data are mean \pm SEM of three independent experiments and analyzed by one-way ANOVA followed by Bonferroni post hoc analysis; ${ }^{* * *} p<0.001$, hCG $(0 \mathrm{~h})$ versus hCG $(7 \mathrm{~h})$ and hCG $(14 \mathrm{~h})$ versus hCG $(21 \mathrm{~h})$. The lower panel (scale $\mathrm{bar}=30 \mu \mathrm{m}$ ) photographs showing denuded oocytes of corresponding upper panel photographs, scale bar $=50 \mu \mathrm{m}$. COCs, cumulus-oocyte complexes; GV, germinal vesicle; GVBD, germinal vesicle breakdown; hCG, human chorionic gonadotropin; SEM, standard error of mean; PBI, first polar body; PBIl, second polar body; PMSG, pregnant mare's serum gonadotropin; M-II, metaphase-II. 
A
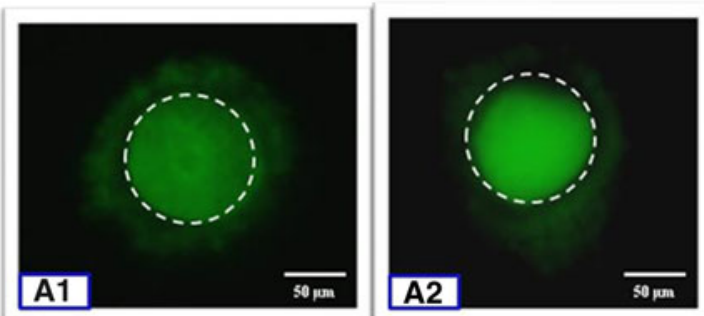

B
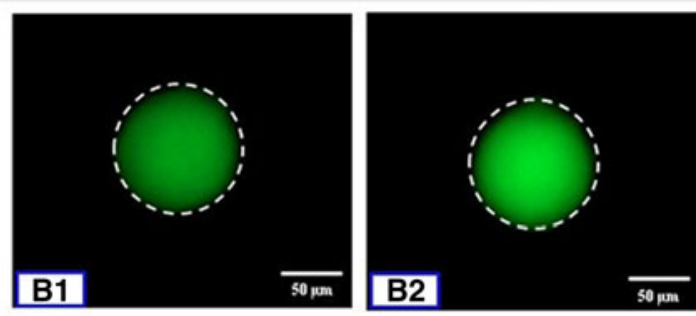

C

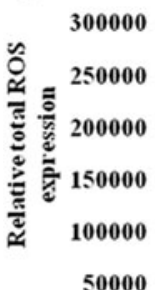

50000

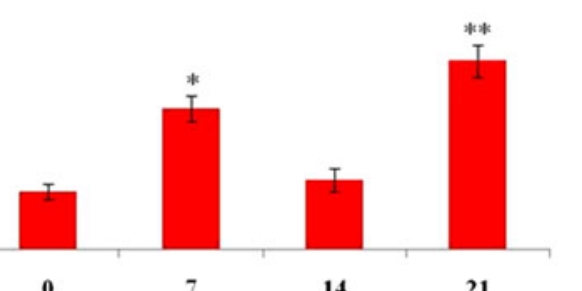

0
7

hCG surge (h)
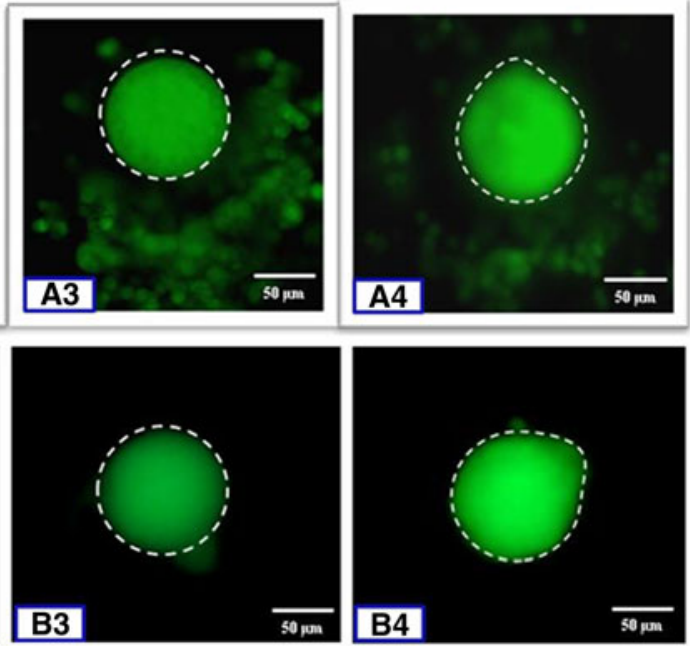

D

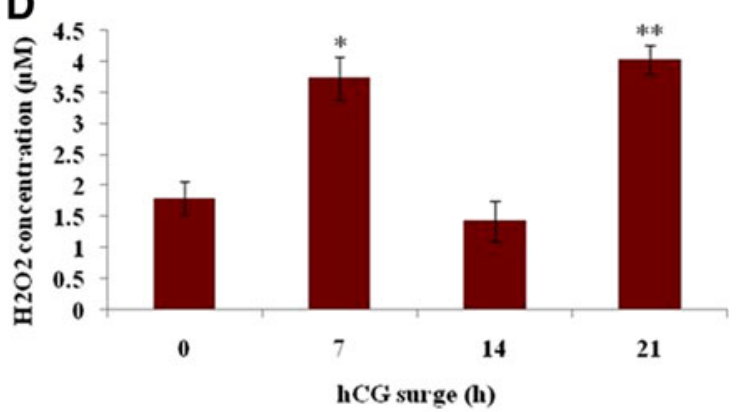

FIG. 2. Changes in total ROS expression and $\mathrm{H}_{2} \mathrm{O}_{2}$ concentration in denuded oocytes. A significant increase of total ROS level was observed in denuded oocytes (B2, B4) of COCs collected after $7 \mathrm{~h}(\mathbf{A 2})$ and $21 \mathrm{~h}$ post-hCG surge (A4) compared to their respective controls (0 h hCG, A1, B1; $14 \mathrm{~h} \mathrm{hCG,} \mathrm{A3,} \mathrm{B3).} \mathrm{The} \mathrm{CTCF}$ analysis of denuded oocytes (B1-4) of COCs (A1-4) further confirms our findings (C). Resumption of meiosis from diplotene ( $7 \mathrm{~h} \mathrm{hCG}$ ), as well as $\mathrm{M}-\mathrm{Il}$ arrest $(21 \mathrm{~h} \mathrm{hCG})$, was associated with a significant increase of intraoocyte $\mathrm{H}_{2} \mathrm{O}_{2}$ concentration compared to their respective controls ( 0 and $14 \mathrm{~h}$ post-hCG surge; D). Data are mean \pm SEM of three independent experiments and analyzed by one-way ANOVA followed by Bonferroni post hoc analysis; ${ }^{*} p<0.05,0 \mathrm{~h} \mathrm{hCG}$ versus $7 \mathrm{~h}$ hCG and ${ }^{* *} p<0.01,14 \mathrm{~h}$ hCG versus $21 \mathrm{~h} \mathrm{hCG}$ scale bar $=50 \mu \mathrm{m}$. CTCF, corrected total cell fluorescence; ROS, reactive oxygen species.

initiation of extrusion of second polar body (PBII), a morphological sign of EM-II arrest (pink arrow; Fig. 1D). The various meiotic stages such as diplotene arrest (Fig. 1E), EDA (Fig. 1F), M-II arrest (Fig. 1G), and EM-II arrest (Fig. 1H) were further confirmed using Hoechst staining. As shown in Figure 1I, majority of follicular oocytes were arrested at diplotene stage after $48 \mathrm{~h}$ of PMSG $+\mathrm{hCG}$ $(0 \mathrm{~h})$ surge. In contrast, hCG surge for $7 \mathrm{~h}$ triggered meiotic resumption from diplotene arrest in majority $(68.2 \% \pm 1.5 \%)$ of oocytes, while $14 \mathrm{~h}$ post-hCG surge induced M-II stage in most of the freshly ovulated oocytes $(96.2 \% \pm 0.8 \%)$. In addition, $21 \mathrm{~h}$ post-hCG surge showed meiotic exit from M-II arrest as evidenced by the initiation of extrusion of PBII in majority of oocytes $(87.4 \% \pm 2.9 \%)$ (one-way ANOVA, $F=579.03, p<0.001$; Fig. 1I).

Increase of ROS and $\mathrm{H}_{2} \mathrm{O}_{2}$ levels associates with meiotic exit from diplotene,

as well as M-II arrest

Figure 2 shows fluorescence intensity of total ROS level in COCs and their corresponding denuded oocyte and $\mathrm{H}_{2} \mathrm{O}_{2}$ concentration in denuded oocytes. Generation of ROS has been observed as evidenced by increase of ROS specific fluorescence intensity in denuded oocytes (Fig. 2B2, B4) of COCs collected after $7 \mathrm{~h}$ (Fig. 2A2) and $21 \mathrm{~h}$ post hCG surge (Fig. 2A4) compared to their 
A
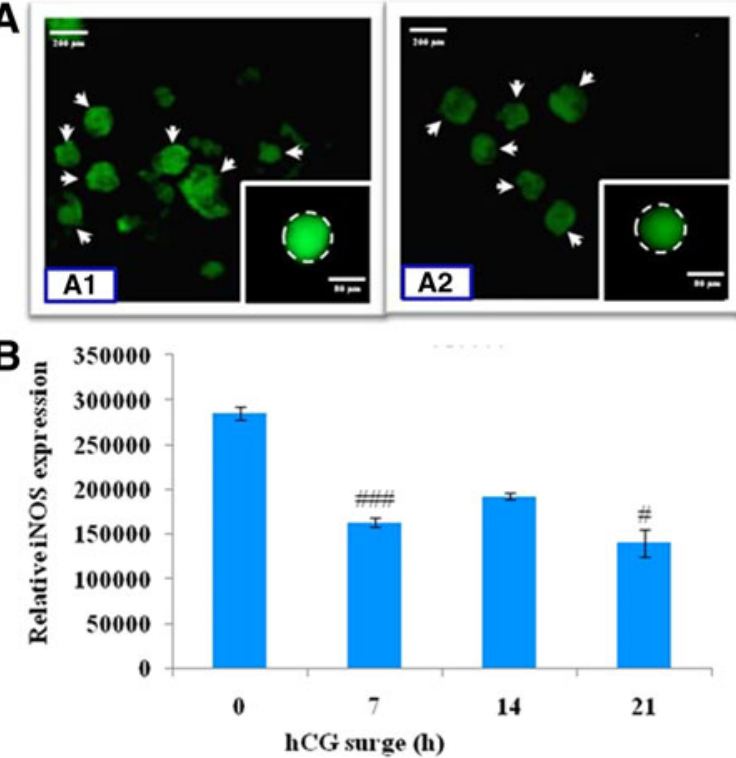
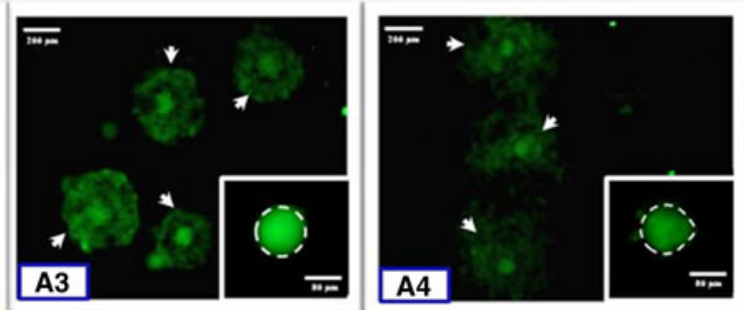

\section{90}

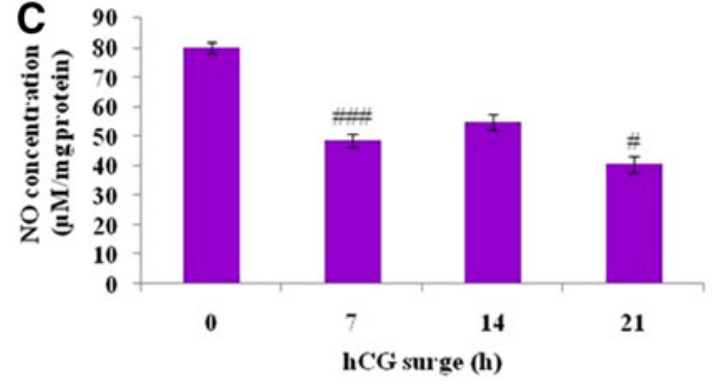

FIG. 3. Changes in iNOS expression and total NO levels in denuded oocytes. $h C G$ surge decreased iNOS immunofluorescence intensity in oocyte collected after $7 \mathrm{~h}$ (A2) and $21 \mathrm{~h}$ post-hCG surge (A4) compared to their respective controls ( 0 and $14 \mathrm{~h}$ post-hCG surge; A1, A3). The CTCF analysis of denuded oocyte (A1-4, in box) of corresponding COCs (white arrows) further confirms our observations (B). A significant decrease in total NO level was observed after 7 and $21 \mathrm{~h}$ of post-hCG surge compared to their respective controls $(0$ and $14 \mathrm{~h}$ post-hCG surge; $\mathbf{C}$ ). Data are mean \pm SEM of three independent experiments and analyzed by one-way ANOVA followed by Bonferroni post hoc analysis; ${ }^{\# \# \# ~} p<0.001$, hCG $(0 \mathrm{~h})$ versus $\mathrm{hCG}(7 \mathrm{~h})$ and ${ }^{\#} p<0.05$, hCG (14h) versus hCG $(21 \mathrm{~h})$; COCs, scale bar $=200 \mu \mathrm{m}$; denuded oocyte, scale bar $=80 \mu \mathrm{m}$. iNOS, inducible nitric oxide synthase; NO, nitric oxide.

respective controls (diplotene arrest, Fig. 2A1, B1; M-II arrest, Fig. 2A3, B3). The CTCF analysis of denuded oocytes (Fig. 2B1-B4) of corresponding COCs (Fig. 2A1A4) using ImageJ software further confirms our findings (Fig. 2C; one-way ANOVA, $F=24.86, p<0.001$ ). Furthermore, resumption of meiosis from diplotene arrest was associated with a significant increase $(p<0.05)$ of intraoocyte $\mathrm{H}_{2} \mathrm{O}_{2}$ concentration $(3.73 \pm 0.34 \mu \mathrm{M})$ compared to diplotene arrest $(1.80 \pm 0.26 \mu \mathrm{M})$. The $\mathrm{H}_{2} \mathrm{O}_{2}$ concentration was declined during $\mathrm{M}$-II arrest after $14 \mathrm{~h}$ post-hCG surge $(1.43 \pm 0.33 \mu \mathrm{M})$. The $\mathrm{H}_{2} \mathrm{O}_{2}$ concentration was further increased significantly $(p<0.05)$ after $21 \mathrm{~h}$ post-hCG surge $(3.6 \pm 0.46 \mu \mathrm{M}$; Fig. $2 \mathrm{D}$; oneway ANOVA, $F=20.19, p<0.001)$.

\section{hCG surge decreases iNOS expression}

and total NO level

As shown in Figure 3A, a decrease $(p<0.05)$ of iNOS expression was noticed in oocyte collected after $7 \mathrm{~h}$ (Fig. 3A2) and $21 \mathrm{~h}$ post-hCG surge (Fig. 3A4) compared to their respective controls (diplotene arrest, $0 \mathrm{~h} \mathrm{hCG}$,
Fig. 3A1; M-II arrest, $14 \mathrm{~h}$ hCG, Fig. 3A3). The CTCF analysis of denuded oocyte (Fig. 3A1-A4, in box) of corresponding COCs confirms our observations (Fig. 3B; one-way ANOVA, $F=48.63, p<0.001)$. A significant decrease $(p<0.05)$ of total NO level was observed during meiotic resumption from diplotene arrest after $7 \mathrm{~h}$ $(48.47 \pm 2.26 \mu \mathrm{M} / \mathrm{mg}$ protein) and $21 \mathrm{~h}(40.47 \pm 2.77$ $\mu \mathrm{M} / \mathrm{mg}$ protein) of post-hCG surge compared to their respective controls (diplotene arrest, $80.07 \pm 1.88 \mu \mathrm{M} /$ mg protein; M-II arrest, $54.83 \pm 2.75 \mu \mathrm{M} / \mathrm{mg}$ protein; Fig. 3C; one-way ANOVA, $F=49.08, p<0.001)$.

\section{hCG surge did not alter Bax, $\mathrm{Bcl}-2$, as well}

as cytochrome c expression levels

As shown in Figure 4, hCG surge did not modulate Bax (Fig. 4A1-A4), Bcl-2 (Fig. 4C1-C4), as well as cytochrome c expressions (Fig. 4E1-E4), as evidenced by their unaltered immunofluorescence intensity during the entire study. Peripheral granulosa cells of $21 \mathrm{~h}$ posthCG surge showed little reduced $\mathrm{Bcl}-2$ expression and increased Bax expression, but it was not significantly altered 


\section{A}
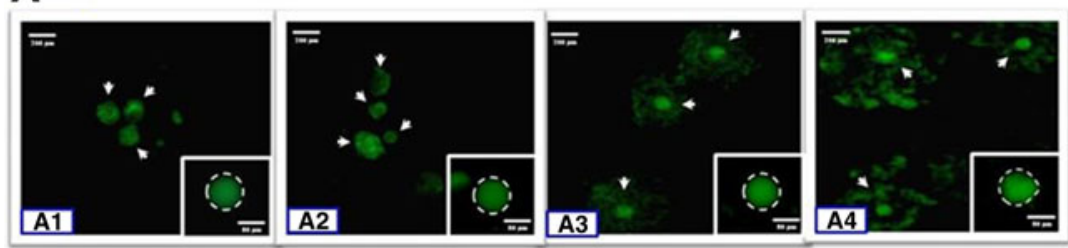

C
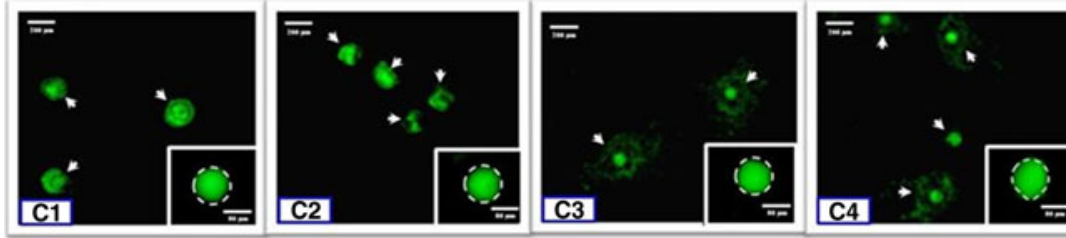

E
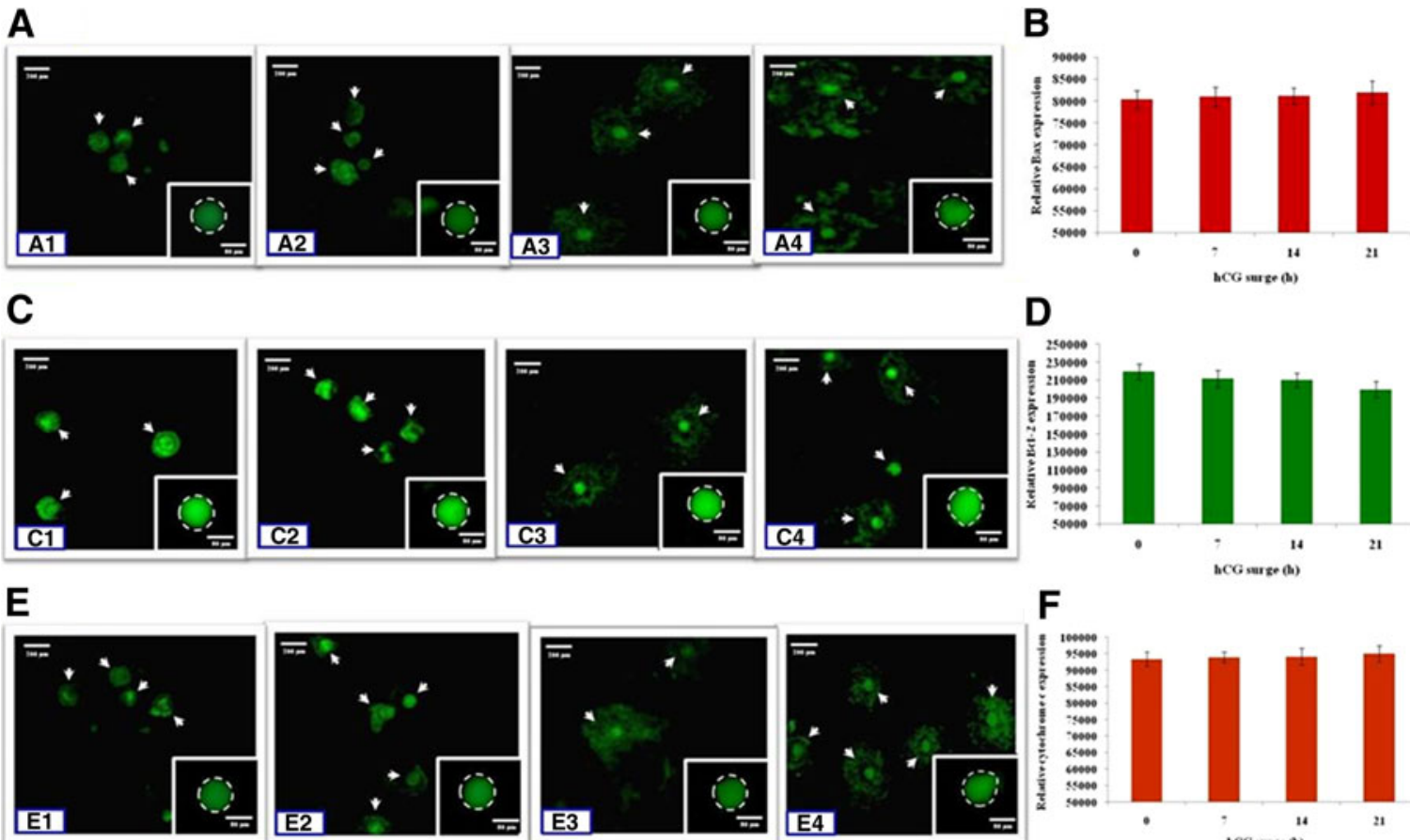

D
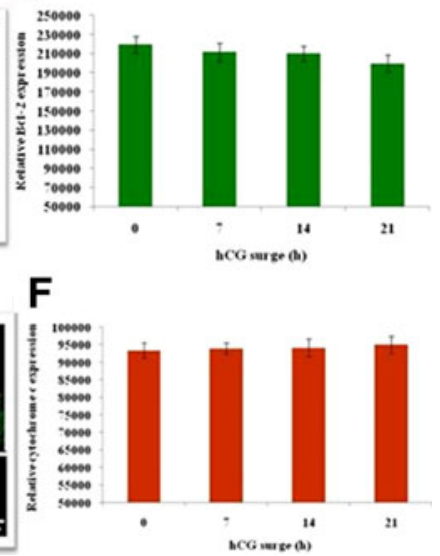

FIG. 4. Representative photograph showing hCG-mediated changes in $\mathrm{Bax}, \mathrm{BCl}-2$, and cytochrome $\mathrm{C}$ expression levels in COCs. The hCG (20 IU) surge did not alter Bax (A1-4), Bcl-2 (C1-4), and cytochrome C (E1-4) expression in COCs. The CTCF analysis of denuded oocyte (in box) of corresponding COCs (white arrows) further confirms above observations (B, D, F). Data are mean \pm SEM of three independent experiments and analyzed by one-way ANOVA. COCs, scale bar $=200 \mu \mathrm{m}$; denuded oocyte, scale bar $=80 \mu \mathrm{m}$.

compared to their respective controls (Fig. 4A1-A3, 4C1C4, 4E1-E4). The CTCF analysis of immunofluorescence intensity of denuded oocyte (in box) of corresponding COCs further strengthens our observations (Bax: Fig. 4B; Bcl-2: Fig. 4D; cytochrome c: Fig. 4F).

Increase of TERT expression associates with postovulatory oocyte aging

As shown in Figure 5, hCG surge increased $(p<0.01)$ immunofluorescence intensity of TERT in oocyte that showed meiotic resumption from M-II arrest after $21 \mathrm{~h}$ post-hCG surge (Fig. 5A4) compared to other groups (Fig. 5A1-A3) showing either diplotene or M-II arrest. The CTCF analysis (Fig. 5B) of the denuded oocyte (Fig. 5A1-A4, in box) of corresponding COCs further strengthens our observations (one-way ANOVA; $F=22.12 ; p<0.001)$.

hCG surge did not induce DNA fragmentation As shown in Figure 6, hCG surge did not induce DNA fragmentation in any group of oocytes in the present study as evidenced by TUNEL fluor negative staining (Fig. 6A1-A4) and background green fluorescence of AO (Fig. 6C1-C4). However, peripheral granulosa cells underwent apoptosis as evidenced by TUNEL fluor positive green fluorescence (Fig. 6A4, yellow arrows). The CTCF analysis (Fig. 6B) of the denuded oocyte (Fig. 6A1-A4, in box) further confirms our observations.

For all the immunofluorescence studies, $\beta$-actin was analyzed as a control in parallel. As shown in Figure 7 , $\beta$-actin did not alter during the entire period of hCG surge (Fig. 7A1-A4). The CTCF analysis of denuded oocyte of corresponding COCs further strengthens our observations (Fig. 7B).

\section{Discussion}

Oocyte quality is one of the important factors that directly affects assisted reproductive technologies (ARTs) outcome in several mammalian species, including human. ${ }^{8,46}$ The oocyte quality is solely dependent upon acquisition of meiotic competency in oocyte, that is, spontaneous EDA, progression through M-I to M- 
A

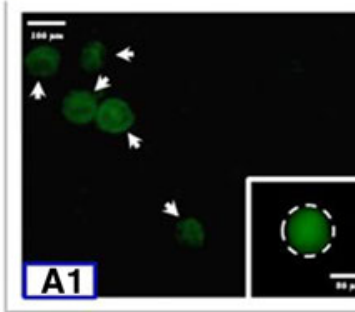

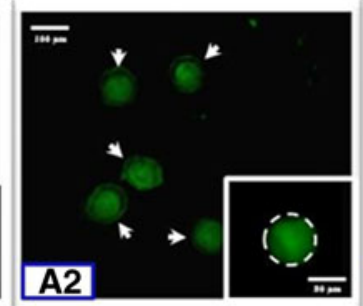
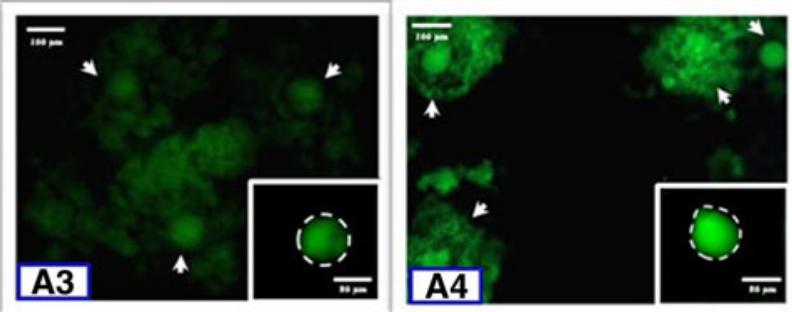

B

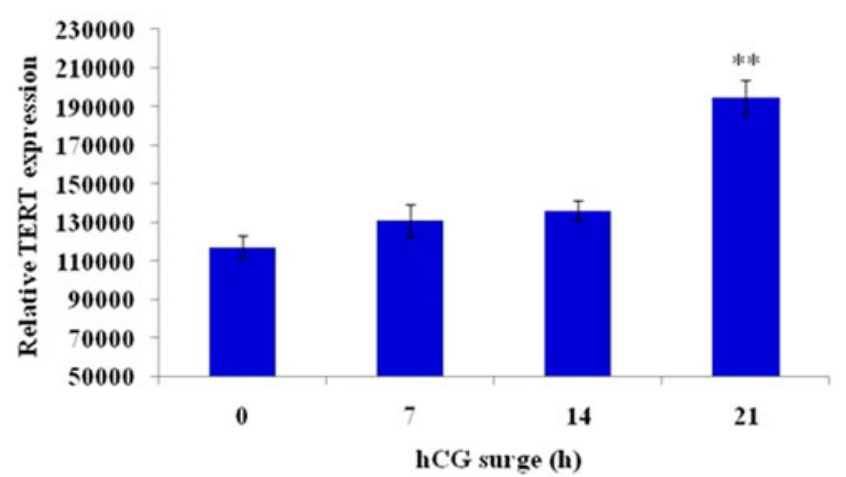

FIG. 5. Representative photograph showing hCG-mediated changes in TERT expression in COCs. A significant increase in TERT expression was observed in oocyte cytoplasm of COCs collected after $21 \mathrm{~h}$ post-hCG surge (A4) compared to other groups (A1-3). The CTCF analysis of denuded oocyte (A1-4, in box) of COCs (white arrows) further strengthens our observations (B). Data are mean \pm SEM of three independent experiments and analyzed by one-way ANOVA followed by Bonferroni post hoc analysis; ${ }^{* *} p<0.01,14 \mathrm{~h}$ hCG versus $21 \mathrm{~h}$ hCG; COCs, scale bar $=100 \mu \mathrm{m}$; denuded oocyte, scale bar $=80 \mu \mathrm{m}$. TERT, telomerase reverse transcriptase.

II, and release of PBI that results in the production of haploid female gamete. A moderate increase of ROS and decrease of NO level may be beneficial for oocyte meiotic resumption. ${ }^{16,17,30}$ High level of ROS could also affect the oocyte quality by inducing apoptosis. ${ }^{31-38}$ The attainment of meiotic competency involves several biochemical and molecular changes. ${ }^{46,47}$ The successful completion of meiotic competency determines oocyte quality, which is primary requirement for successful fertilization and early embryonic development. ${ }^{47,48}$

Oocyte meiotic competency relies on bidirectional communication between the oocyte and surrounding granulosa cells, which is regulated by various endocrine, paracrine, and autocrine factors. ${ }^{48}$ Pituitary gonadotropin surge is the primary requirement for the induction of meiotic maturation in oocytes. ${ }^{28,39}$ hCG has been frequently used as a surrogate for LH surge to induce ovulation in several mammalian species, ${ }^{26,46}$ but its role in meiotic maturation remains ill understood. Data of the present study suggest that most of the oocytes (more than 90\%) collected after $48 \mathrm{~h}$
PMSG surge were arrested at GV stage. The hCG surge for $7 \mathrm{~h}$ triggered meiotic resumption from diplotene stage in more than $65 \%$ of oocytes, while $14 \mathrm{~h}$ hCG surge not only induced granulosa cell dispersion but also pushes oocyte to reach to M-II stage as evidenced by one haploid genome in the oocyte cytoplasm and other toward polar body. The 14-h hCG surge induced PBI extrusion in more than $85 \%$ of oocytes. Furthermore, collection of COCs from ampulla of fallopian tube after $21 \mathrm{~h}$ post-hCG surge resulted in highly dispersed granulosa cells, reduction in number of total granulosa cells encircling oocytes, and meiotic exit from M-II arrest as evidenced by the initiation and extrusion of PBII, haploid genome in PBI area, and formation of metaphase plate in the cytoplasm of ovulated oocytes. The hCG-mediated meiotic exit from M-II arrest has been reported in rat. ${ }^{20,25}$

Meiotic resumption from diplotene arrest could be due to hCG surge that induces final stages of folliculogenesis in mammals. A moderate increase of ROS level has been reported to induce spontaneous meiotic 
A

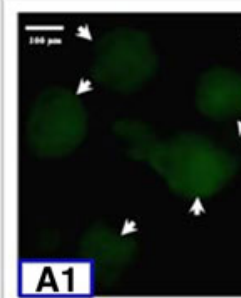

\section{A1}

B

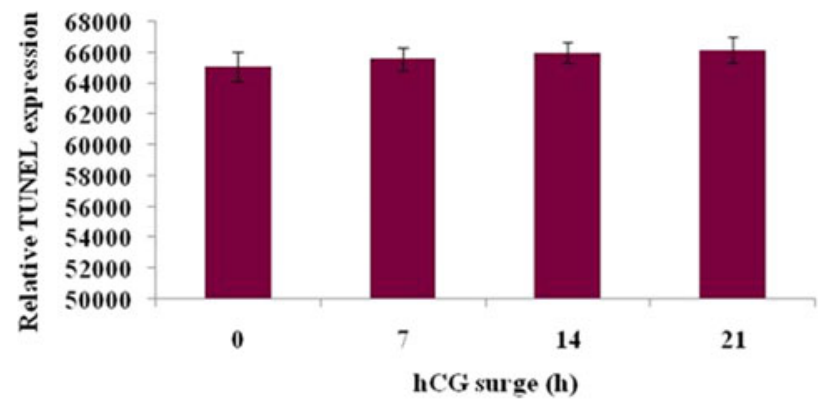

\section{C}
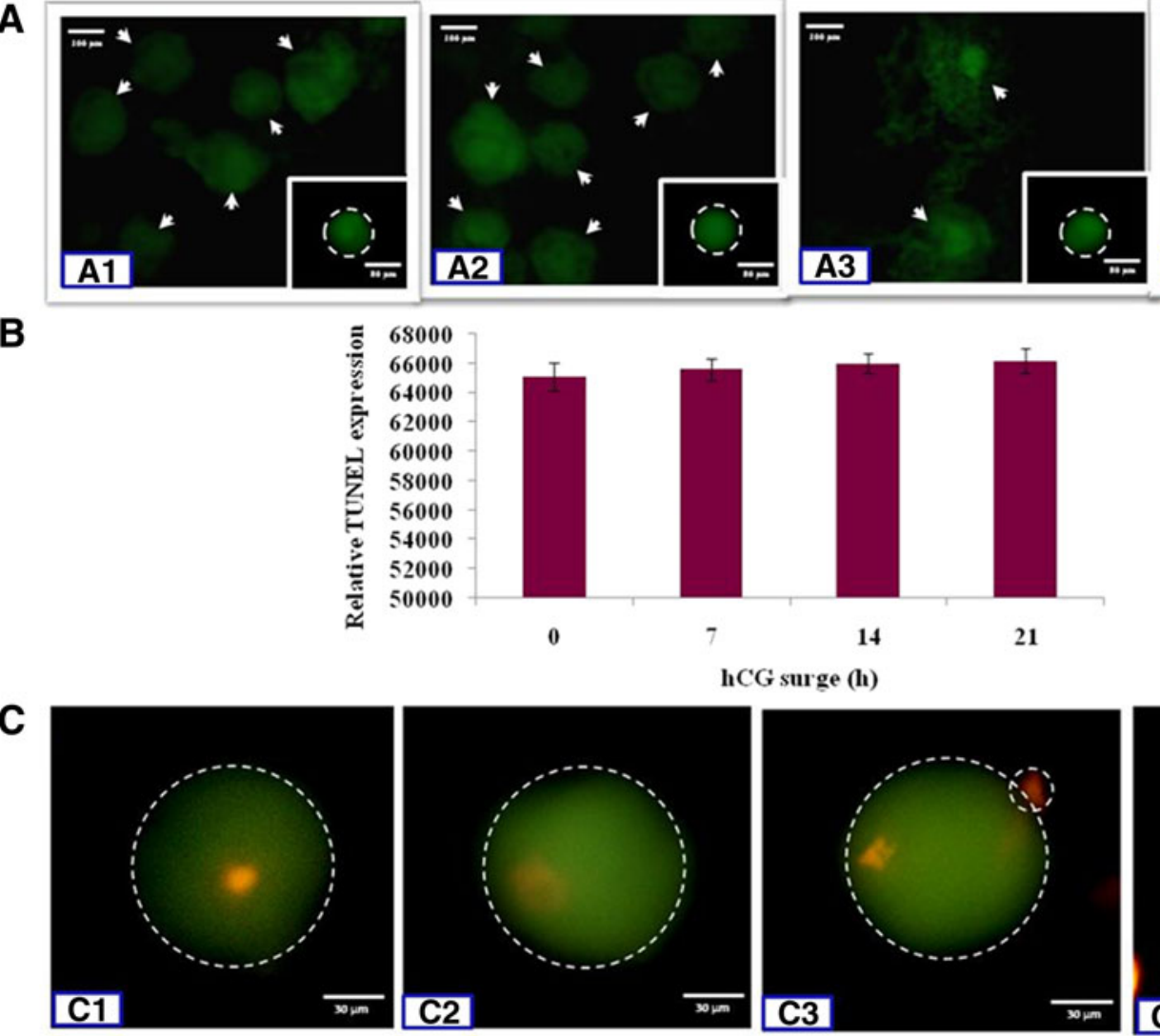
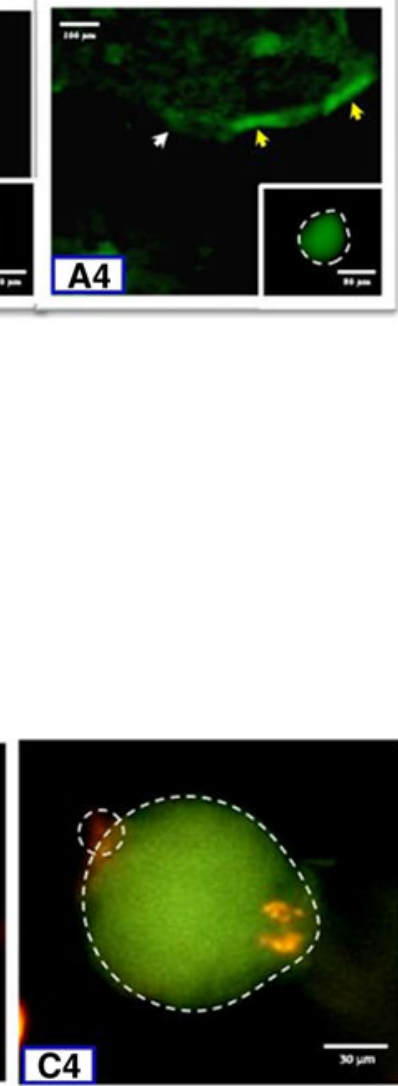

FIG. 6. Representative photograph showing hCG-mediated changes in DNA fragmentation in COCs. The hCG surge did not induce DNA fragmentation as evidenced by TUNEL fluor negative staining (A1-4) and background green fluorescence of AO (C1-4). However, peripheral granulosa cells underwent apoptosis as evidenced by TUNEL fluor positive green staining (A4, yellow arrows). The CTCF analysis of denuded oocyte (A1-4, in box) of COCs (white arrows) further confirms above observations (B). Data are mean \pm SEM of three independent experiments and analyzed by one-way ANOVA. COCs, scale bar $=100 \mu \mathrm{m}$; denuded oocyte, scale bar $=80 \mu \mathrm{m}$.

resumption in rat oocytes ${ }^{16,21}$ and beneficial for fertilization, as well as reproductive outcome, after ovarian stimulation protocol. ${ }^{4,28-30}$ Studies from our laboratory using NO donor and iNOS inhibitor suggest that the reduction in NO level results in spontaneous EDA in rat COCs cultured in vitro. ${ }^{49}$ Our results suggest that the increase of total ROS level (almost two fold increase) was associated with meiotic exit from diplotene, as well as M-II arrest. The increase of ROS, decrease of iNOS, and thereby NO levels after $7 \mathrm{~h}$ of hCG surge could be due to increased cell proliferation and cellular metabolism within the follicle. After $14 \mathrm{~h}$ of hCG surge, follicles are ruptured, and ovulated COCs reside in the ampulla of the fallopian tube. Hence, they are disconnected from follicular mi- croenvironment that leads to a reduction of ROS, iNOS, and NO levels in ovulated COCs. Due to limited energy resources, ovulated COCs in the ampulla of the fallopian tube generate ROS, which could induce apoptosis in peripheral granulosa cells, as well as meiotic exit from M-II arrest that deteriorates oocyte quality. The quantification analysis of $\mathrm{H}_{2} \mathrm{O}_{2}$ level further strengthens our data. Similarly increase of ROS, as well as $\mathrm{H}_{2} \mathrm{O}_{2}$ level, has been reported to induce meiotic exit from diplotene, ${ }^{16}$ as well as M-II arrest. ${ }^{21}$ These data together with our previous findings suggest that hCG surge after superovulation induction generates ROS. This moderate increase of ROS level was sufficient to induce meiotic exit from diplotene, as well as M-II arrest in rat oocytes. 

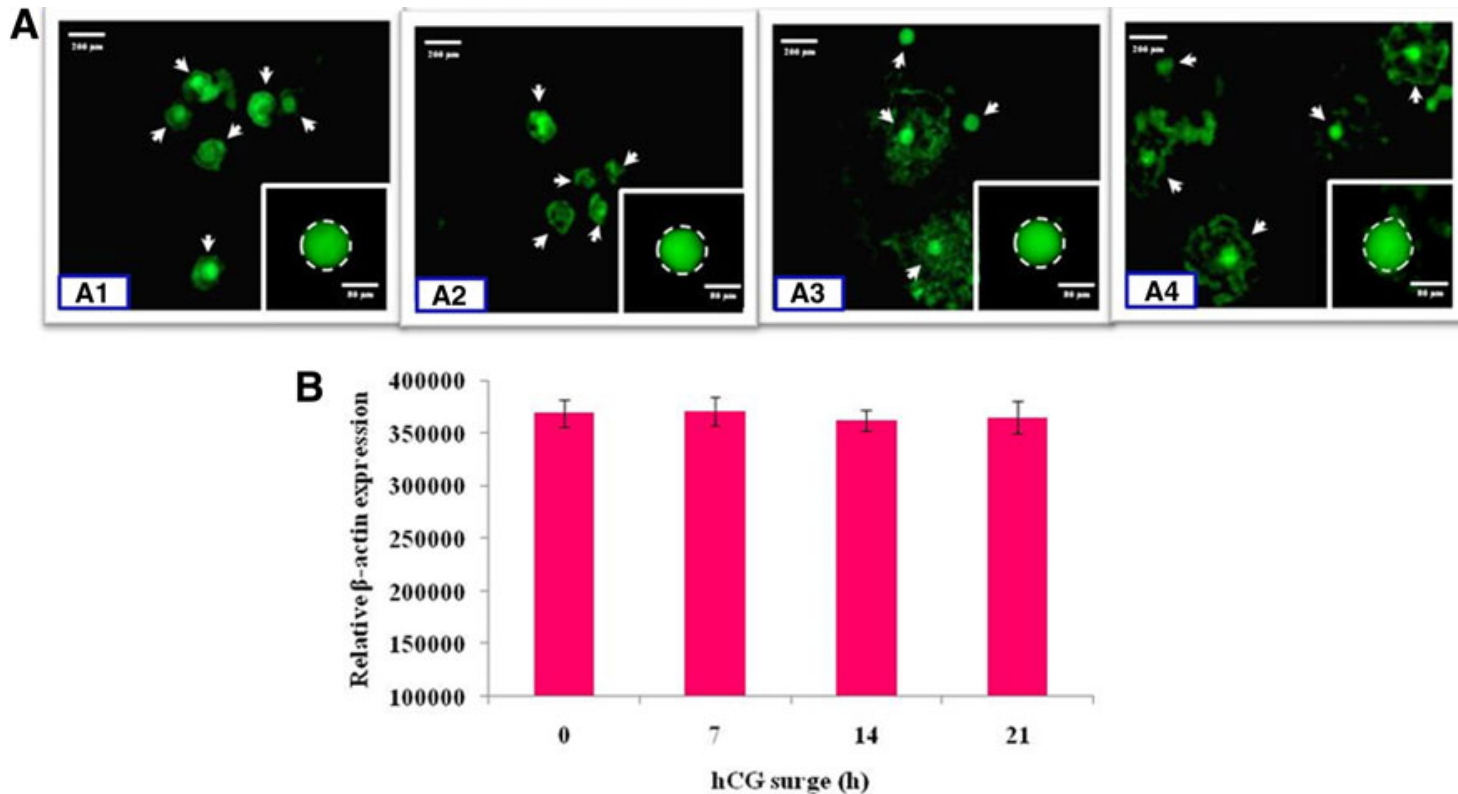

FIG. 7. Representative photograph showing $\beta$-actin expression in COCs. The $\beta$-actin was analyzed as a control for all immunofluorescence studies. The $\beta$-actin expression did not change during the entire period of hCG surge (A1-4). The CTCF analysis of denuded oocyte (A1-4, in box) of COCs (white arrows) further strengthens our observations (B). Data are mean \pm SEM of three independent experiments and analyzed by one-way ANOVA. COCs, scale bar $=200 \mu \mathrm{m}$; denuded oocyte, scale bar $=80 \mu \mathrm{m}$.

The increased level of ROS may stimulate aging process by elevating markers of cell aging. ${ }^{43,44}$ The exposure of increased level of ROS influences telomerase activity and subsequently the length of telomeres in human and bovine ovaries. ${ }^{50,51}$ TERT (telomerase subunit) expression has been found to correlate closely with the telomerase activity ${ }^{45}$; therefore, we analyzed TERT expression in the present study. Our results suggest that TERT expression was not altered till $14 \mathrm{~h}$ posthCG surge, while its expression significantly increased in oocytes after $21 \mathrm{~h}$ post-hCG surge. These data corroborate with previous observations that the increased TERT expression induces meiotic cell cycle progression, as well as oocyte aging. ${ }^{25}$

The increased level of ROS may generate oxidative stress and induce mitochondria-mediated oocyte apoptosis. ${ }^{31-38}$ We propose that hCG surge during superovulation induction increases ROS level that may induce apoptosis in COCs. Data of the present study suggest that accumulation of ROS due to hCG surge was sufficient to induce meiotic exit but not enough to initiate ROS-mediated apoptosis. The hCG-mediated accumulation of ROS was not sufficient to alter Bax, Bcl-2, and cytochrome c levels in the oocyte cytoplasm. Furthermore, increased level of ROS due to hCG surge did not induce DNA fragmentation as evidenced by $\mathrm{AO} / \mathrm{Etbr}$, as well as TUNEL fluor negative staining in oocyte. However, peripheral granulosa cells of COCs collected after $21 \mathrm{~h}$ post-hCG treatment show DNA fragmentation as evidenced by TUNEL fluor positive staining.

In conclusion, data of the present study suggest that hCG-mediated increased level of ROS and decreased NO level was sufficient to induce meiotic exit from diplotene, as well as M-II arrest, but this moderate increase of ROS level was not sufficient to trigger Bax/Bcl-2 and cytochrome c expression levels and DNA fragmentation in oocytes. However, increased TERT expression was observed in oocytes collected $21 \mathrm{~h}$ post-hCG surge showing onset of oocyte aging. Although oocyte experiences aging process, the survival factor and DNA integrity were maintained until $21 \mathrm{~h}$ of hCG surge. Taken together, these results suggest that hCG induces generation of ROS sufficient to trigger meiotic exit from diplotene, as well as M-II arrest, but not good enough to induce apoptosis in rat oocytes. 


\section{Acknowledgment}

This study was financially supported by Department of Science and Technology, Ministry of Science and Technology, Government of India (Grant No. EMR/2014/ 000702).

\section{Author Disclosure Statement}

No competing financial interests exist.

\section{References}

1. Sirard MA, Desrosier S, Assidi M. In vivo and in vitro effects of FSH on oocyte maturation and developmental competence. Theriogenology. 2007;68:S71-S76.

2. Pandey AN, Tripathi A, Premkumar KV, et al. Reactive oxygen and nitrogen species during meiotic resumption from diplotene arrest in mammalian oocytes. J Cell Biochem. 2010;111:521-528.

3. Shkolnik K, Tadmor A, Ben-Dor S, et al. Reactive oxygen species are indispensable in ovulation. Proc Natl Acad Sci U S A. 2011;108:14621467.

4. Agarwal A, Durairajanayagam D, du Plessis SS. Utility of antioxidants during assisted reproductive techniques: an evidence based review. Reprod Biol Endocrinol. 2014;12:112.

5. Chen ZQ, Ming TX, Nielsen HI. Maturation arrest of human oocytes at germinal vesicle stage. J Hum Reprod Sci. 2010;3:153-157.

6. Tripathi A, Kumar KV, Chaube SK. Meiotic cell cycle arrest in mammalian oocytes. J Cell Physiol. 2010;223:592-600.

7. Tiwari M, Prasad S, Tripathi A, et al. Involvement of reactive oxygen species in meiotic cell cycle regulation and apoptosis in mammalian oocytes. Reactive Oxygen Species. 2016;1:110-116.

8. Chaube SK, Prasad S, Tiwari M, et al. Rat: an interesting model to study oocyte meiosis in mammals. RRJZS. 2016;4:25-27.

9. Gilchrist RB. Recent insights into oocyte-follicle cell interactions provide opportunities for the development of new approaches to in vitro maturation. Reprod Fertil Dev. 2011;23:23-31.

10. Wang ZW, Zhang GL, Schatten $\mathrm{H}$, et al. Cytoplasmic determination of meiotic spindle size revealed by a unique inter-species germinal vesicle transfer model. Sci Rep. 2016;6:19827.

11. Tiwari M, Prasad S, Shrivastav TG, et al. Calcium signaling during meiotic cell cycle regulation and apoptosis in mammalian oocytes. J Cell Physiol. 2017;232:976-981.

12. Tiwari M, Prasad S, Pandey AN, et al. Nitric oxide signaling during meiotic cell cycle regulation in mammalian oocytes. Front Biosci (Schol Ed). 2017;9:307-318.

13. Gupta A, Tiwari M, Prasad S, et al. Role of cyclic nucleotide phosphodiesterases during meiotic resumption from diplotene arrest in mammalian oocytes. J Cell Biochem. 2017;180:446-452.

14. Albertini DF. A cell for every season: the ovarian granulosa cell. J Assist Reprod Genet. 2011;28:877-878.

15. Chang HM, Qiao J, Leung PC. Oocyte-somatic cell interactions in the human ovary-novel role of bone morphogenetic proteins and growth differentiation factors. Hum Reprod Update 2017;23:1-18.

16. Pandey AN, Chaube SK. A moderate increase of hydrogen peroxide level is beneficial for spontaneous resumption of meiosis from diplotene arrest in rat oocytes cultured in vitro. Biores Open Access 2014;3:183191.

17. Pandey AN, Chaube SK. Reduction of nitric oxide level leads to spontaneous resumption of meiosis in diplotene-arrested rat oocytes cultured in vitro. Exp Biol Med (Maywood). 2015;240:15-25.

18. Tiwari M, Chaube SK. Moderate increase of reactive oxygen species triggers meiotic resumption in rat follicular oocytes. J Obstet Gynaecol Res 2016;42:536-546.

19. Chebotareva T, Taylor J, Mullins JJ, et al. Rat eggs cannot wait: spontaneous exit from meiotic metaphase-II arrest. Mol Reprod Dev. 2011;78:795-807.

20. Premkumar KV, Chaube SK. Nitric oxide signals postovulatory aginginduced abortive spontaneous egg activation in rats. Redox Rep. 2015;20:184-192.
21. Premkumar KV, Chaube SK. Increased level of reactive oxygen species persuades postovulatory aging mediated spontaneous egg activation in rat eggs cultured in vitro. In Vitro Cell Dev Biol Anim. 2016;52:576-588.

22. Prasad S, Tiwari M, Tripathi $A$, et al. Changes in signal molecules and maturation promoting factor levels associate with spontaneous resumption of meiosis in rat oocytes. Cell Biol Int. 2015;39:759-769.

23. Prasad S, Tiwari M, Pandey AN, et al. Impact of stress on oocyte quality and reproductive outcome. J Biomed Sci. 2016;23:36.

24. Prasad S, Tiwari M, Chaube SK. Abortive spontaneous egg activation: an emerging biological threat for the existence of mammals. Cell Reprogram. 2017;19:145-149.

25. Prasad S, Chaube SK. Increased telomerase reverse transcriptase expression level associates with spontaneous exit from $\mathrm{M}$-II arrest in rat eggs. Cell Reprogram. 2017;19:27-34.

26. Zhang $M$, Ouyang $H$, Xia G. The signal pathway of gonadotropins-induced mammalian oocyte meiotic resumption. Mol Hum Reprod. 2009;15:399409.

27. Zhou CJ, Wu SN, Shen JP, et al. The beneficial effects of cumulus cells and oocyte-cumulus cell gap junctions depend on oocyte maturation and fertilization methods in mice. PeerJ. 2016;4:e1761.

28. Casarini L, Riccetti L, de Pascali F, et al. Estrogen modulates specific life and death signals induced by LH and hCG in human primary granulosa cells in vitro. Int J Mol Sci. 2017;18:926.

29. Oyawoye O, Abdel Gadir A, Garner A, et al. Antioxidants and reactive oxygen species in follicular fluid of women undergoing IVF: relationship to outcome. Hum Reprod. 2003;18:2270-2274.

30. Combelles CM, Gupta S, Agarwal A. Could oxidative stress influence the in-vitro maturation of oocytes? Reprod Biomed Online. 2009;18: 864-880.

31. Chaube SK, Prasad PV, Thakur SC, et al. Hydrogen peroxide modulates meiotic cell cycle and induces morphological features characteristic of apoptosis in rat oocytes cultured in vitro. Apoptosis. 2005;10:863-874.

32. Chaube SK, Shrivastav TG, Tiwari M, et al. Neem (Azadirachta indica L.) leaf extract deteriorates oocyte quality by inducing ROS-mediated apoptosis in mammals. Springerplus. 2014;3:464.

33. Tripathi A, Khatun S, Pandey AN, et al. Intracellular levels of hydrogen peroxide and nitric oxide in oocytes at various stages of meiotic cell cycle and apoptosis. Free Radic Res. 2009;43:287-294.

34. Tripathi A, Shrivastav TG, Chaube SK. An increase of granulosa cell apoptosis mediates aqueous neem (Azadirachta indica) leaf extract induced oocyte apoptosis in rat. Int J Appl Basic Med Res. 2013;3:27-36.

35. Cheng Y, Yata A, Klein C, et al. Oocyte-expressed interleukin 7 suppresses granulosa cell apoptosis and promotes oocyte maturation in rats. Biol Reprod. 2011;84:707-714.

36. Tripathi A, Chaube SK. Roscovitine inhibits extrusion of second polar body and induces apoptosis in rat eggs cultured in vitro. Pharmacol Report. 2015;67:866-874.

37. Tiwari M, Prasad S, Tripathi A, et al. Apoptosis in mammalian oocytes: a review. Apoptosis. 2015;20:1019-1025.

38. Tiwari M, Tripathi A, Chaube SK. Presence of encircling granulosa cells protects against oxidative stress-induced apoptosis in rat eggs cultured in vitro. Apoptosis. 2017;22:98-107.

39. Theofanakis $C$, Drakakis $P$, Besharat A, et al. Human chorionic gonadotropin: the pregnancy hormone and more. Int J Mol Sci. 2017;18:1059.

40. Basini G, Grasselli F. Nitric oxide in follicle development and oocyte competence. Reproduction. 2015;150:R1-R9.

41. Jablonka-Shariff A, Olson LM. Hormonal regulation of nitric oxide synthases and their cell-specific expression during follicular development in the rat ovary. Endocrinology. 1997;138:460-468.

42. Miao YL, Liu XY, Qiao TW, et al. Cumulus cells accelerate aging of mouse oocytes. Biol Reprod. 2005;73:1025-1031.

43. Lord T, Aitken RJ. Oxidative stress and ageing of the post-ovulatory oocyte. Reproduction. 2013;146:R217-R227.

44. Liang LF, Qi ST, Xian YX, et al. Protective effect of antioxidants on the prematuration aging of mouse oocytes. Sci rep. 2017;7:1434.

45. Ozturk S, Sozen B, Demir N. Telomere length and telomerase activity during oocyte maturation and early embryo development in mammalian species. Mol Hum Reprod. 2014;20:15-30.

46. Ma M, Wang J, Xu L, et al. Effects of two human chorionic gonadotropin doses administered to the ovarian states during the in vitro fertilization and embryo transfer program. Biomed Rep. 2015;3:215-219. 
47. Campen KA, McNatty KP, Pitman JL. A protective role of cumulus cells after short-term exposure of rat cumulus cell-oocyte complexes to lifestyle or environmental contaminants. Reprod Toxicol. 2017;69: 19-33.

48. Liu W, Xin $Q$, Wang $X$, et al. Estrogen receptors in granulosa cells govern meiotic resumption of pre-ovulatory oocytes in mammals. Cell Death Dis. 2017;8:e2662.

49. Tiwari M, Chaube SK. Reduction of nitric oxide level results in maturation promoting factor destabilization during spontaneous meiotic exit from diplotene arrest in rat cumulus oocytes complexes cultured in vitro. Dev Growth Differ. 2017; DOI: 10.1111/dgd.12390.

50. Goto H, Iwata $\mathrm{H}$, Takeo $\mathrm{S}$, et al. Effect of bovine age on the proliferative activity, global DNA methylation, relative telomere length and telomerase activity of granulosa cells. Zygote 2011;21:256-264.

51. Cheng $\mathrm{EH}$, Chen SU, Lee $\mathrm{TH}$, et al. Evaluation of telomere length in $\mathrm{Cu}-$ mulus cells as a potential biomarker of oocyte and embryo quality. Hum Reprod. 2013;28:929-936.

Cite this article as: Tiwari M, Chaube SK (2017) Human chorionic gonadotropin mediated generation of reactive oxygen species is sufficient to induce meiotic exit but not apoptosis in rat oocytes, BioResearch Open Access 6:1, 110-122, DOI: 10.1089/biores.2017.0018.

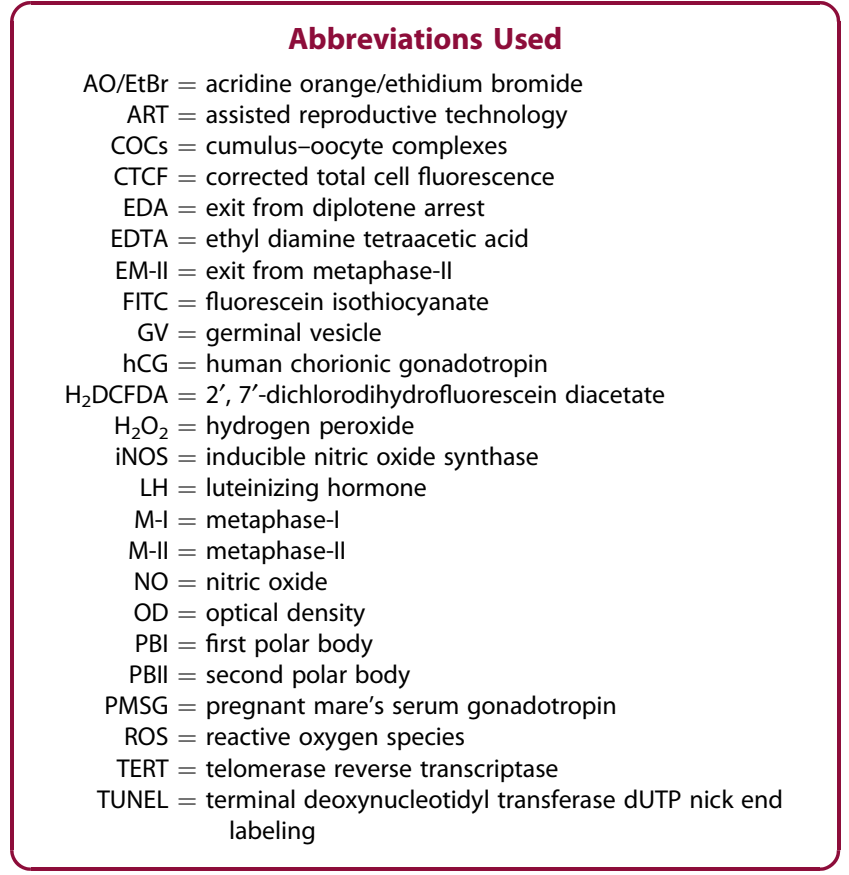

\section{Publish in BioResearch Open Access}

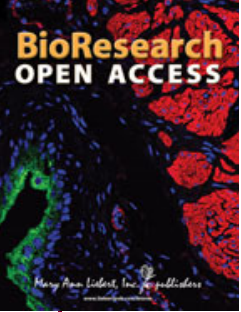

- Broad coverage of biomedical research - Immediate, unrestricted online access - Rigorous peer review

- Compliance with open access mandates

- Authors retain copyright

- Highly indexed

- Targeted email marketing

liebertpub.com/biores 